\title{
Utilising satellite-based techniques to identify and monitor slope instabilities: the Fagraskógarfjall and Limnes landslides
}

\author{
H Larkin CGG Satellite Mapping, UK \\ N Magnall CGG Satellite Mapping, UK \\ A Thomas CGG Satellite Mapping, UK \\ R Holley CGG Satellite Mapping, UK \\ H McCormack CGG Satellite Mapping, UK
}

\begin{abstract}
Slope instabilities can be highly disruptive, leading to damage to infrastructure, halting of mine operations, and, in the worst cases, loss of life. Slope instabilities can range in severity from slow-moving landslides (moving at millimetres per year) to catastrophic mass failure events (moving at many metres per second and involving tens of millions of cubic metres of material). Timely identification of the early stages of slope instability, whether in an artificial or a natural slope, is essential to properly mitigate the impacts of such hazards.
\end{abstract}

Here we demonstrate how satellite remote sensing can be used to identify and monitor unstable slopes. By applying interferometric synthetic aperture radar (InSAR) processing techniques to open-access Sentinel-1 radar data, we are able to identify and quantify displacement associated with two very different landslides. In the case of the Fagraskógarfjall landslide, Iceland, we are able to monitor a rapidly accelerating slope instability up to the point where mass failure of the slope occurs. For the Limnes landslide, Cyprus, we are able to categorically identify and monitor a slow-moving slope instability that impacted the community living on the slope. Furthermore, we identify clear correlations between meteorological conditions and the rate of slope displacement.

Our results highlight the effectiveness of InSAR and, more broadly, earth observation for monitoring unstable slopes. The increasing proliferation of earth observation missions, and the trend towards open-access data, means that utilising InSAR for slope monitoring is increasingly feasible, and becoming widely adopted.

Keywords: landslide, InSAR, remote sensing, monitoring

\section{$1 \quad$ Introduction}

Detecting and monitoring landslides and slope instabilities are of critical importance. Slope instabilities can be dangerous (potentially leading to loss of life) and expensive (potentially leading to disruption of commercial activities or requiring costly mitigation strategies). Monitoring of slope instabilities can be challenging, often requiring the installation of expensive monitoring equipment, as well as the deployment of people into potentially hazardous areas. Satellite remote sensing and, specifically, interferometric synthetic aperture radar (InSAR), provides a complimentary monitoring technique that can cover wide areas effectively and at relatively low cost. Here we demonstrate how InSAR has been used to remotely monitor two contrasting landslides: the first, a slow-moving landslide in Cyprus and the second, a rapidly creeping landslide in Iceland that developed into a mass failure event in 2018.

The Limnes slope sits to the southeast of the old town of Pissouri in southwest Cyprus (Figure 1, white dashed line). It is a shallow $\left(\sim 10^{\circ}\right)$ slope approximately $1 \mathrm{~km}$ in length facing to the east. Land use includes a mixture of farmland and residential buildings. Cyprus has a Mediterranean climate with long, hot and dry summers and mild winters. Most rainfall occurs in the winter, between November and February, when average rainfall ranges from 52-98 mm/month. Evidence of ground displacement, such as damage to buildings, walls and 
pavements, began to occur in 2012 (Hearn et al. 2018; Larkin \& Hearn 2019). Previous studies have used InSAR to examine the deformation of the slope (Hearn et al. 2018; Larkin \& Hearn 2019; Perdikou \& Kouhartsiouk 2019) and this study builds upon that previous work.

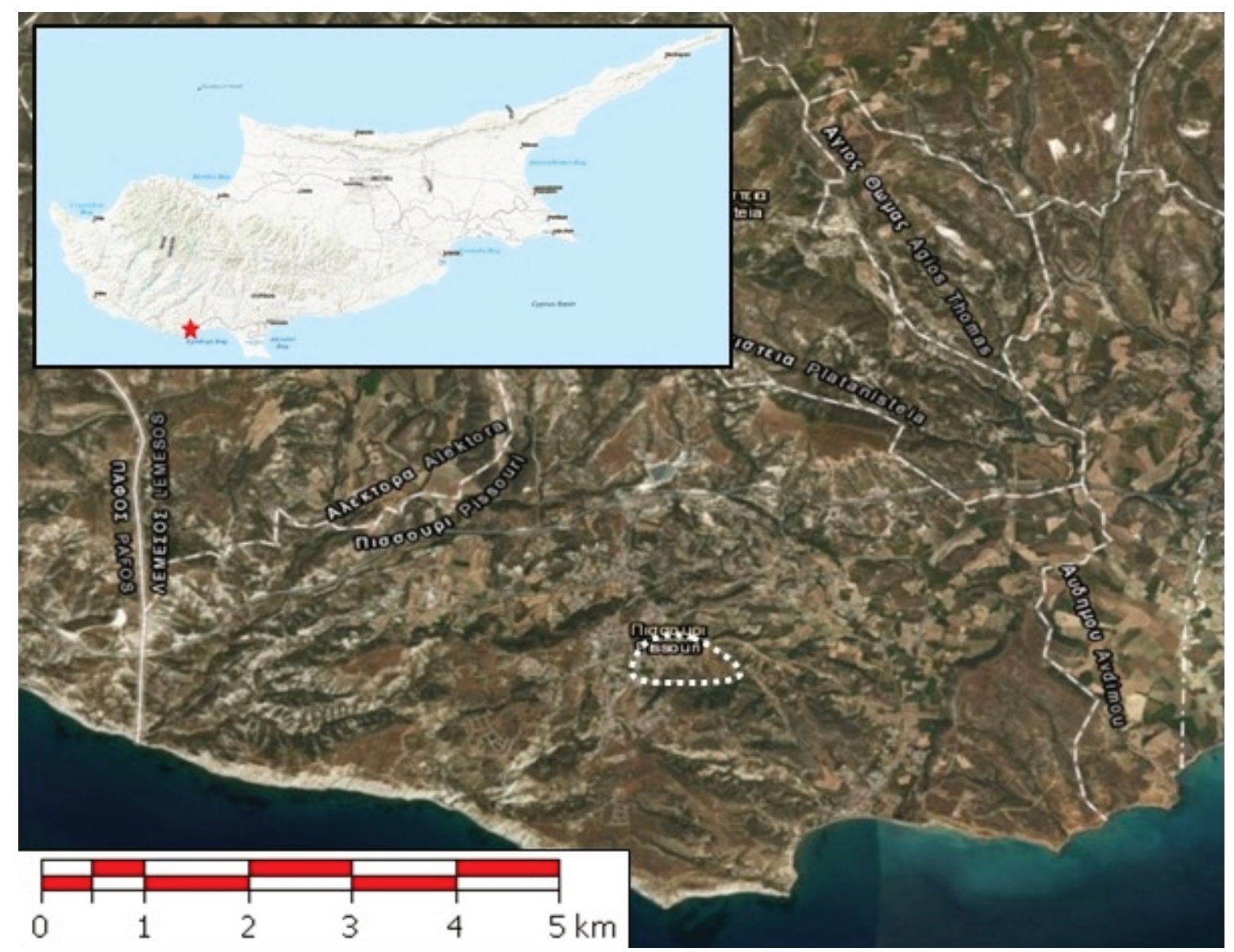

Figure 1 Location of the Limnes landslide (white dashed line) and Pissouri within Cyprus (red star on inset). Background image courtesy of Esri, DigitalGlobe, GeoEye, Earthstar Geographics, CNES/Airbus, USDA, AeroGRID, IGN, and the GIS User Community

The Fagraskógarfjall landslide is located in western Iceland (Figure 2, white dashed line). Iceland has a subarctic climate with long, cold winters and short, mild summers. Most precipitation falls between September and April when precipitation ranges from $40-160 \mathrm{~mm} /$ month. The landslide failed on the morning of 7 July 2018 . The initial landslide had an estimated volume of 7 million $\mathrm{m}^{3}$ of material but upon collapse, the landslide entrained more material, giving a final volume of between 10 and 20 million $\mathrm{m}^{3}$ (Icelandic Meteorological Office 2018). The landslide occurred in a remote part of Iceland so there was no risk to infrastructure or people. However, the unexpected occurrence of this landslide poses greater questions about whether similar landslides could be identified before they pose a risk. Steep sided and sudden landslides such as this are often preceded by creep, and InSAR is well suited to the detection of this displacement. 


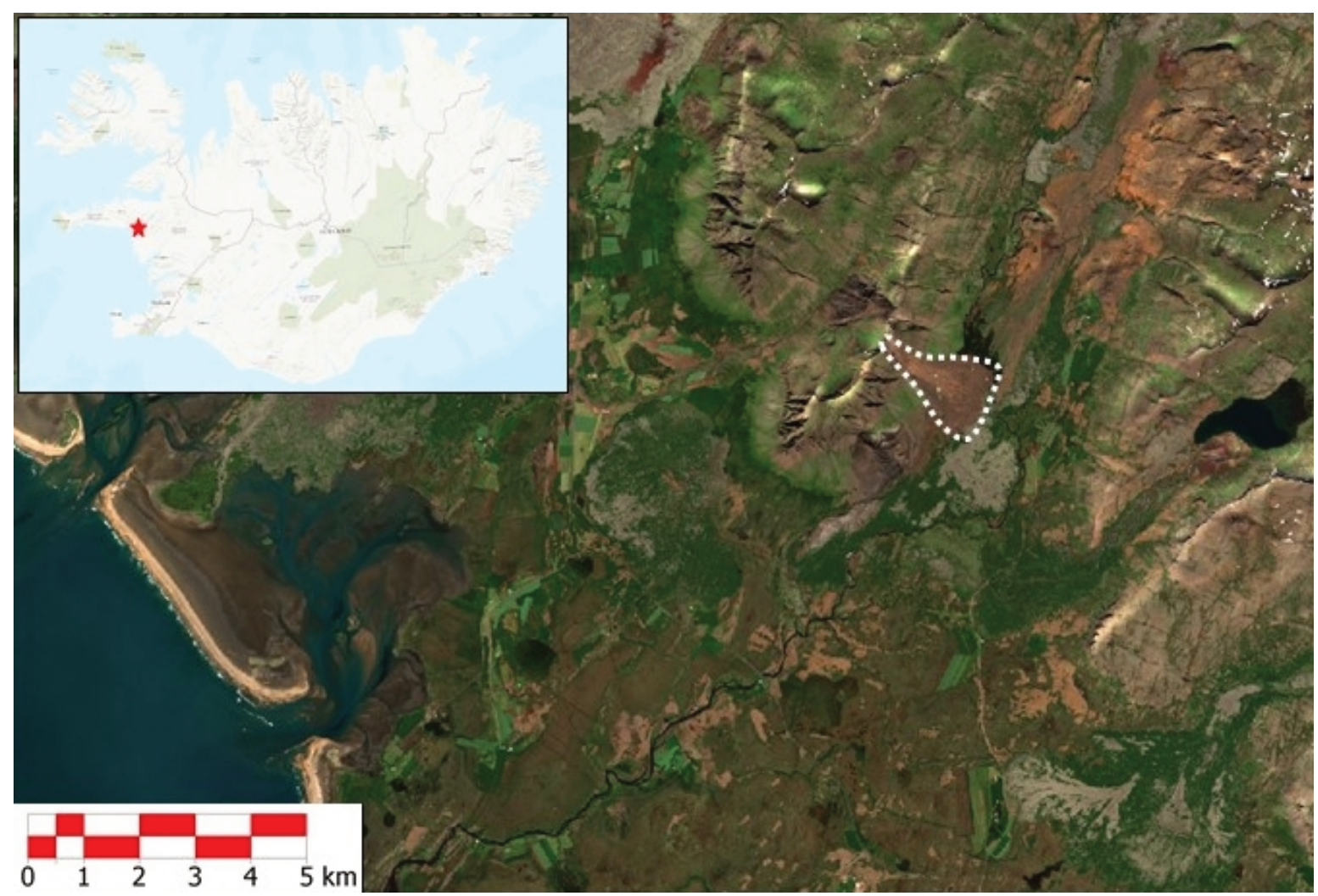

Figure 2 Location of the Fagraskógarfjall landslide (white dashed line) and Fagraskógarfjall within Iceland (red star on inset). Background image courtesy of Esri, DigitalGlobe, GeoEye, Earthstar Geographics, CNES/Airbus, USDA, AeroGRID, IGN, and the GIS User Community

These two landslides present contrasting slope instabilities, both of which can be effectively monitored using InSAR. These cases demonstrate the effectiveness of remote sensing in monitoring active landslides or slopes that are at risk of displacement, whether natural or man-made.

\section{Methodology}

Satellite remote sensing covers a wide range of techniques and applications. This study primarily uses satellite InSAR to detect ground displacement across two landslides. We also utilise local meteorological data to determine the impact of rainfall on the rate of displacement of the landslides.

\section{$2.1 \quad \operatorname{InSAR}$}

InSAR uses satellite synthetic aperture radar (SAR) imagery to detect ground displacement. A SAR image contains two components:

1. The amplitude, which is a measure of the strength of the returned radar signal, can be used to generate an image.

2. The phase, which is a measure of the returned wavelength of the radar signal.

By comparing the phase of two radar images of the same location taken at different times, it is possible to quantify subtle changes in elevation, a technique known as differential interferometry (DifSAR). By using a more advanced technique based on the conventional DifSAR approach which compares multiple SAR images instead, it is possible to generate a time series of displacement. This advanced DifSAR technique was used to generate displacement results for both study areas in this paper. Using large stacks of SAR images, networks of SAR image pairs were processed to determine changes in radar phase through time, from which phase changes due to displacement were then extracted. Changes to radar phase are not only caused by ground 
displacement but also topography, orbital errors, atmospheric artefacts and system noise. A good quality digital elevation model (DEM) is required to remove the impact of topography, where a DEM may be inaccurate this can lead to corresponding errors in the InSAR result. Subtle inaccuracies in orbital positioning of the satellite can also lead to errors in radar phase, but these can be corrected. Most significantly, atmospheric conditions can impact the measured phase. Atmospheric water vapour can delay the radar signal, leading to a shift in the measured phase and therefore apparent displacement. Atmospheric errors can be correlated with elevation (and therefore modelled and removed), but are often spatially and temporally heterogeneous, which can be more challenging to mitigate. Once the phase components attributed to topography, orbital positioning and atmospheric conditions are modelled and removed, the phase component related to displacement remains. A more detailed description of SAR interferometry can be found in Bamler \& Hart (1998), Rosen et al. (2000) and Hanssen (2001).

Unlike some monitoring techniques, InSAR does not provide an absolute measurement of ground displacement. Instead, it provides a relative measurement with respect to a reference point that is either assumed to be stable or constrained using an alternative survey method.

Displacement rates of millimetres to metres can be accurately detected using InSAR. However, for InSAR to accurately detect such large magnitude displacement, the deformation gradient must not be too high $(\sim 2.5 \mathrm{~cm}$ of displacement between any two pixels and/or acquisition dates). Adjacent pixels can only move by so much (typically a few centimetres) before the phase values of the pixels become so noisy that it is not possible to determine the amount of ground displacement. InSAR also requires that the ground conditions are similar between two SAR images (termed coherence), and when sufficient changes to the ground surface occur, measurement points can be lost. Large changes to the ground surface and therefore, a loss of coherence, can occur due to a number of factors, such as fresh snowfall, construction activities, or large ground displacements such as a slope failure. Provided the limitations of the technique are properly understood, and errors are mitigated where possible, InSAR can provide precise measurements of ground displacement.

\section{$2.2 \quad$ Data sources}

A combination of SAR imagery, DEMs, and meteorological data were used as part of this study. Sentinel-1 SAR imagery was used for InSAR analysis. This is an open-access C-band satellite mission from the Copernicus programme (https://scihub.copernicus.eu) that acquires data every 12 days globally and every six days across Europe and other regions of scientific interest. Sentinel-1 has a spatial resolution of approximately $20 \mathrm{~m}$. Sentinel-1 began acquiring images in 2014 and continues to do so.

DEMs used for the processing were obtained from the Shuttle Radar Topography Mission (SRTM) (Jarvis et al. 2008) and the Arctic DEM (Porter et al. 2018). SRTM was generated from radar data collected in 2000 and the global 1-arc second ( $30 \mathrm{~m}$ ) version was released in 2015. The Arctic DEM was released in 2018 and has a resolution of $2 \mathrm{~m}$.

Meteorological data, specifically rainfall data, was acquired from local weather stations. Rainfall data for Cyprus was acquired from the Cyprus Department of Meteorology. Rainfall data for Iceland was acquired from the Icelandic Meteorological Office.

\section{$3 \quad$ Results}

\subsection{Limnes, Cyprus}

Ground displacement results were derived across the Limnes slope for the time period October 2014 to December 2017. Two stacks of SAR data were procured; a total of 132 scenes on the ascending (south-tonorth) orbit of the satellite and 127 scenes on the descending (north-to-south) orbit of the satellite. Images were acquired at between 6 - and 48-day intervals. Analysing imagery from both ascending and descending orbits gives ground displacement measurements in two different lines-of-sight (LOS) geometries, which can then be combined and decomposed into a vertical displacement component and a horizontal displacement 
component (in the east-west direction). Due to the orbit directions of the satellites, satellite InSAR is relatively insensitive to displacement in the horizontal north-south plane, however, given the east-facing aspect of the Limnes slope, this was not a limitation in this case. Table 1 details the geometry of each orbit including the line-of-sight bearing (from north) and incidence angle (from vertical).

Table 1 Sentinel-1 satellite viewing geometries for Limnes, Cyprus

\begin{tabular}{llll}
\hline Satellite & Orbit & Line-of-sight bearing & Incidence angle \\
\hline Sentinel-1 & Ascending & $080^{\circ}$ & $39^{\circ}$ \\
Sentinel-1 & Descending & $281^{\circ}$ & $38^{\circ}$ \\
\hline
\end{tabular}

The extent of the landslide is clearly visible in the InSAR displacement rate map (Figure 3). The landslide is $\sim 900 \mathrm{~m}$ long and $\sim 500 \mathrm{~m}$ wide. The displacement is predominantly horizontal, with over $200 \mathrm{~mm} /$ year of eastward displacement of the landslide (Figure 3a). There is a lesser vertical component to the displacement, with up to $40 \mathrm{~mm} /$ year of subsidence on the upper landslide and $20 \mathrm{~mm} /$ year of heave on the lower landslide (Figure $3 \mathrm{~b}$ ). This combination of subsidence and heave on the landslide could be indicative of rotational slip of the slope.

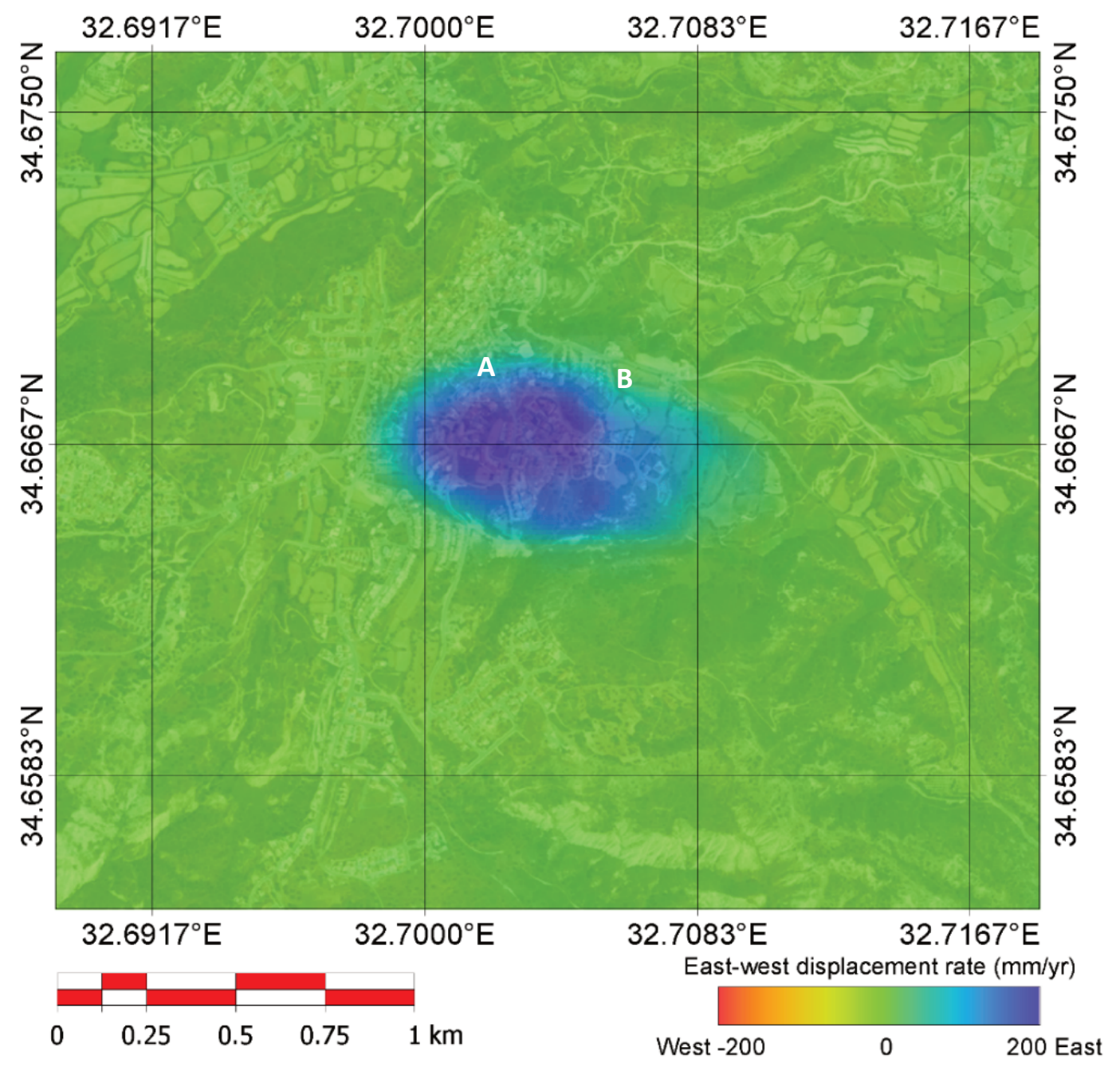

(a) 


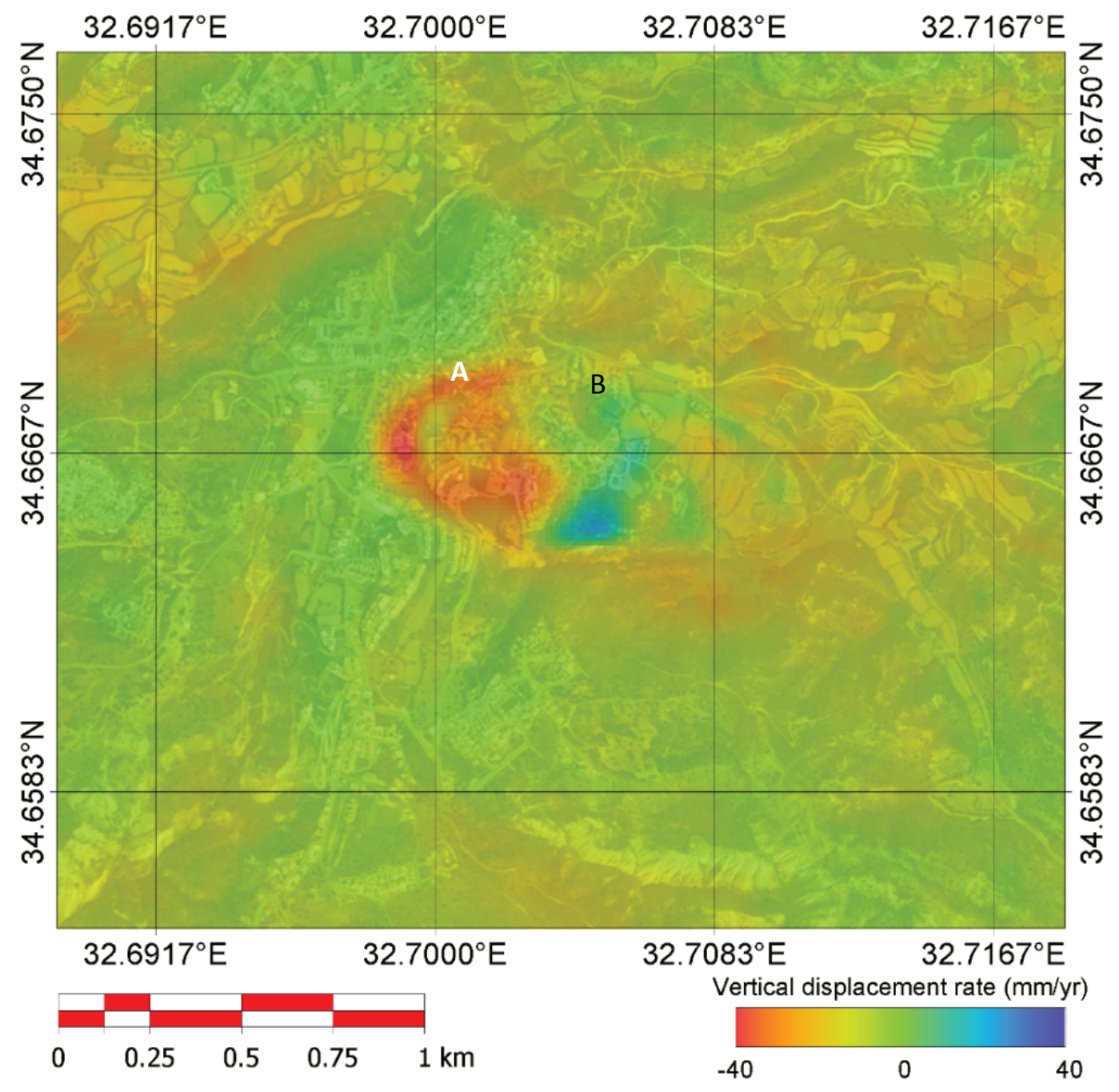

(b)

Figure 3 InSAR displacement rates for the Limnes landslide for the time period 17 October 2014 to 30 December 2017. Points A and B represent the upper and lower landslide respectively. Contains modified Copernicus Sentinel data, 2019. (a) East-west displacement of the slope, 17 October 2014 to 30 December 2017, positive values represent eastward displacement; (b) Vertical displacement rate, 17 October 2014 to 30 December 2017, negative values represent subsidence and positive values represent heave

Since 17 October 2014, the Limnes slope has undergone variable displacement, with up to $90 \mathrm{~mm}$ of subsidence and $25 \mathrm{~mm}$ of heave on the upper and lower portions of the landslide respectively (Figure 4a). The slope has also moved eastward by up to $450 \mathrm{~mm}$ (Figure 4b). The displacement of the slope was temporally heterogeneous and rapidly accelerated from January 2017 (Figure 4).

The rate of slope displacement has an apparent correlation with rainfall (Hearn et al. 2018). Some wetter time periods, such as December 2014 and December 2016, appear to correspond with increases in the displacement rate of the landslide (Figure 4). The increase in the displacement rate in June 2017 is also associated with an unusually wet month, with $20 \mathrm{~mm}$ of rainfall as opposed to typical rainfall of $0.7 \mathrm{~mm}$ (Figure 4). In some cases, it appears that there may be a lag between higher rainfall and increased displacement of the landslide, with increases in displacement rate following months of heavier rainfall. 


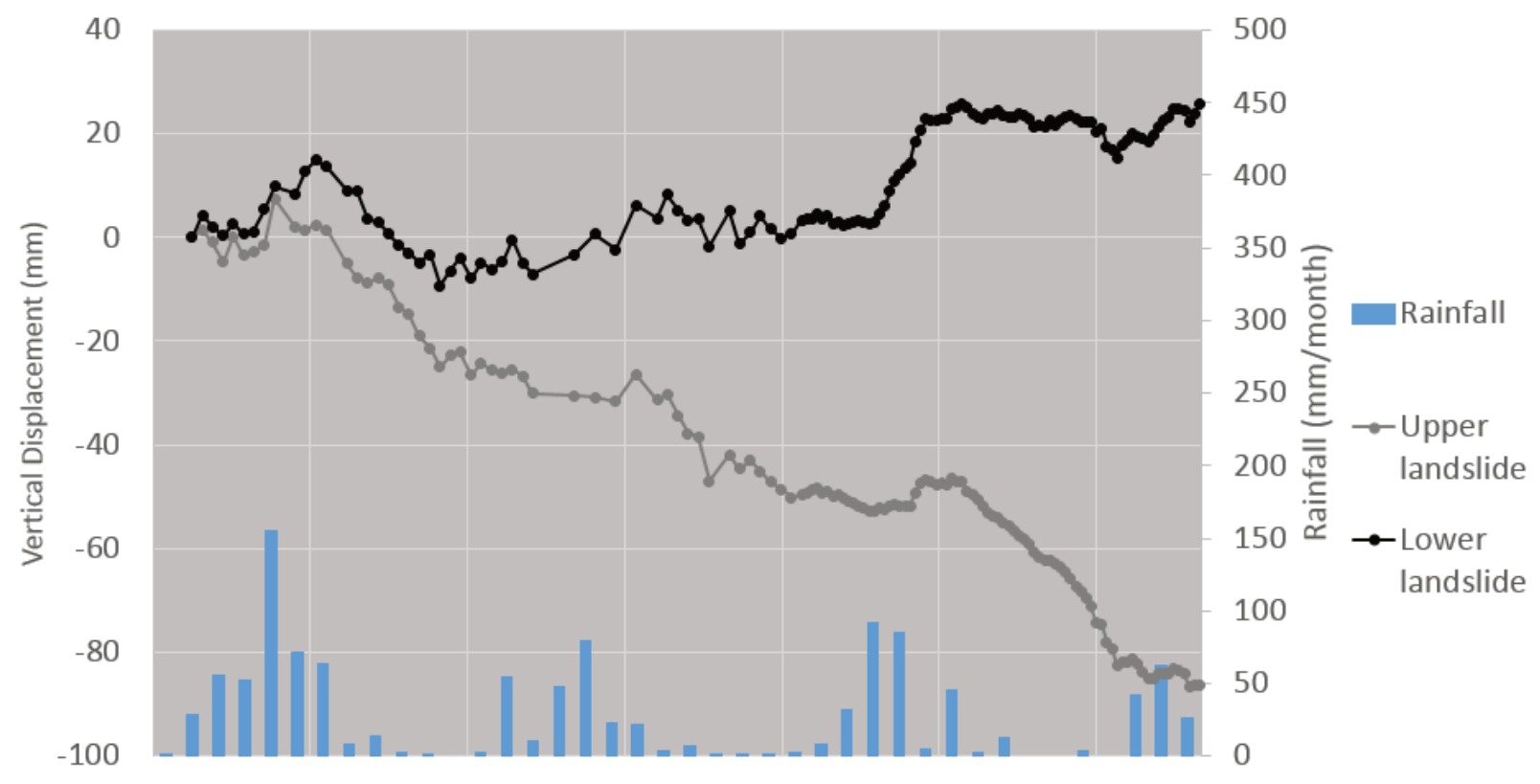

Sep-2014 Mar-2015 Sep-2015 Mar-2016 Sep-2016 Mar-2017 Sep-2017

Date

(a)

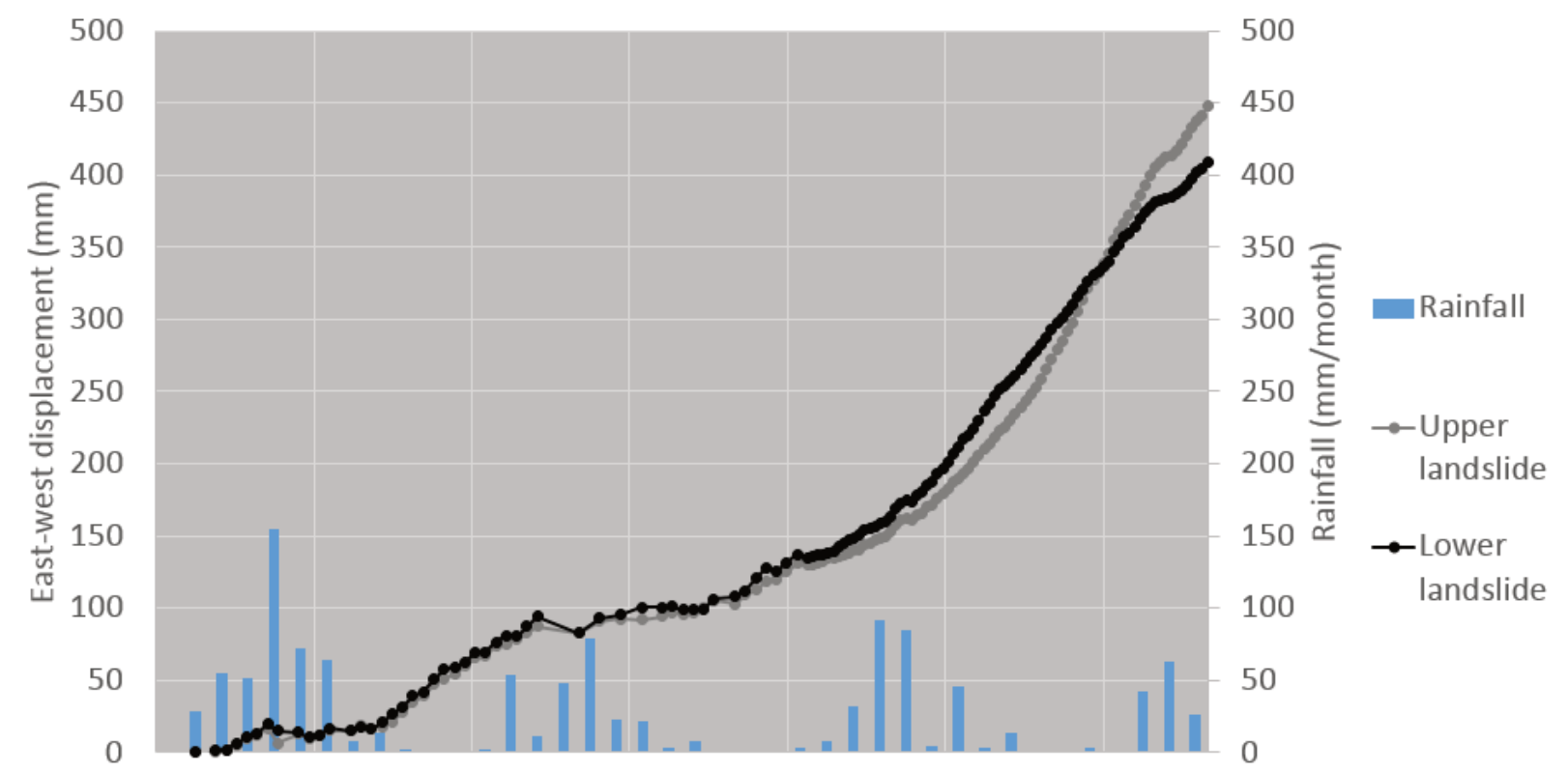

Sep-2014 Mar-2015 Sep-2015 Mar-2016 Sep-2016 Mar-2017 Sep-2017

Date

(b)

Figure 4 Displacement of the Limnes landslide and total monthly rainfall. (a) Vertical displacement of the upper and lower landslide; (b) East-west displacement of the upper and lower landslide, positive values represent eastward displacement and negative values westward displacement

\subsection{Fagraskógarfjall, Iceland}

Ground displacement results were generated across the Fagraskógarfjall landslide for the summers of 2015, 2016, 2017 and 2018. A single ascending stack of SAR imagery was procured and processed. This was acquired at 6- and 12-day intervals. Prior to 2017, only 12-day interval data was available. From 2017 onwards, 6-day data was available. The shorter time difference between images made it possible to accurately measure a 
greater magnitude of displacement. In total, 130 individual SAR scenes were available prior to the landslide event, however, it was only possible to use data acquired during snow-free times of year (typically June to October) as it is not possible to generate robust InSAR results over snow-covered ground. Only a single LOS was processed across this site and so all results are LOS measurements. The viewing geometry of the image acquisitions is shown in Table 2.

Table 2 Sentinel-1 satellite viewing geometry for Fagraskógarfjall, Iceland

\begin{tabular}{llll}
\hline Satellite & Orbit & LOS bearing & Incidence angle \\
\hline Sentinel-1 & Ascending & $080^{\circ}$ & $39^{\circ}$ \\
\hline
\end{tabular}

The pre-failure extent of the landslide is clearly visible from InSAR, as is the post-failure extent and subsequent instabilities (Figure 5). The extent of pre-failure displacement was $\sim 600 \mathrm{~m}$ in length and $300 \mathrm{~m}$ in width (Figure 5a) and post-failure the landslide was $\sim 2,000 \mathrm{~m}$ long and $\sim 1,600 \mathrm{~m}$ wide (Figure $5 \mathrm{~b}$ ). In summer 2015, slope displacement of up to $30 \mathrm{~mm}$ away from the satellite LOS was detected between 9 July 2015 and 7 September 2015 (Figure 6a). It was only possible to generate reliable measurements in these three months as in June and October, the landslide was moving at a higher rate, exceeding the displacement gradient that InSAR can reliably detect $(\sim 2.5 \mathrm{~cm}$ of displacement between any two pixels and/or acquisition dates). Between 27 July 2016 and 25 September 2016, up to $30 \mathrm{~mm}$ of displacement was detected, similar to the magnitude of displacement detected between July and September 2015 (Figure 6b). In 2016, it was also not possible to obtain reliable measurements in June and October due to the high rate of displacement on the slope.

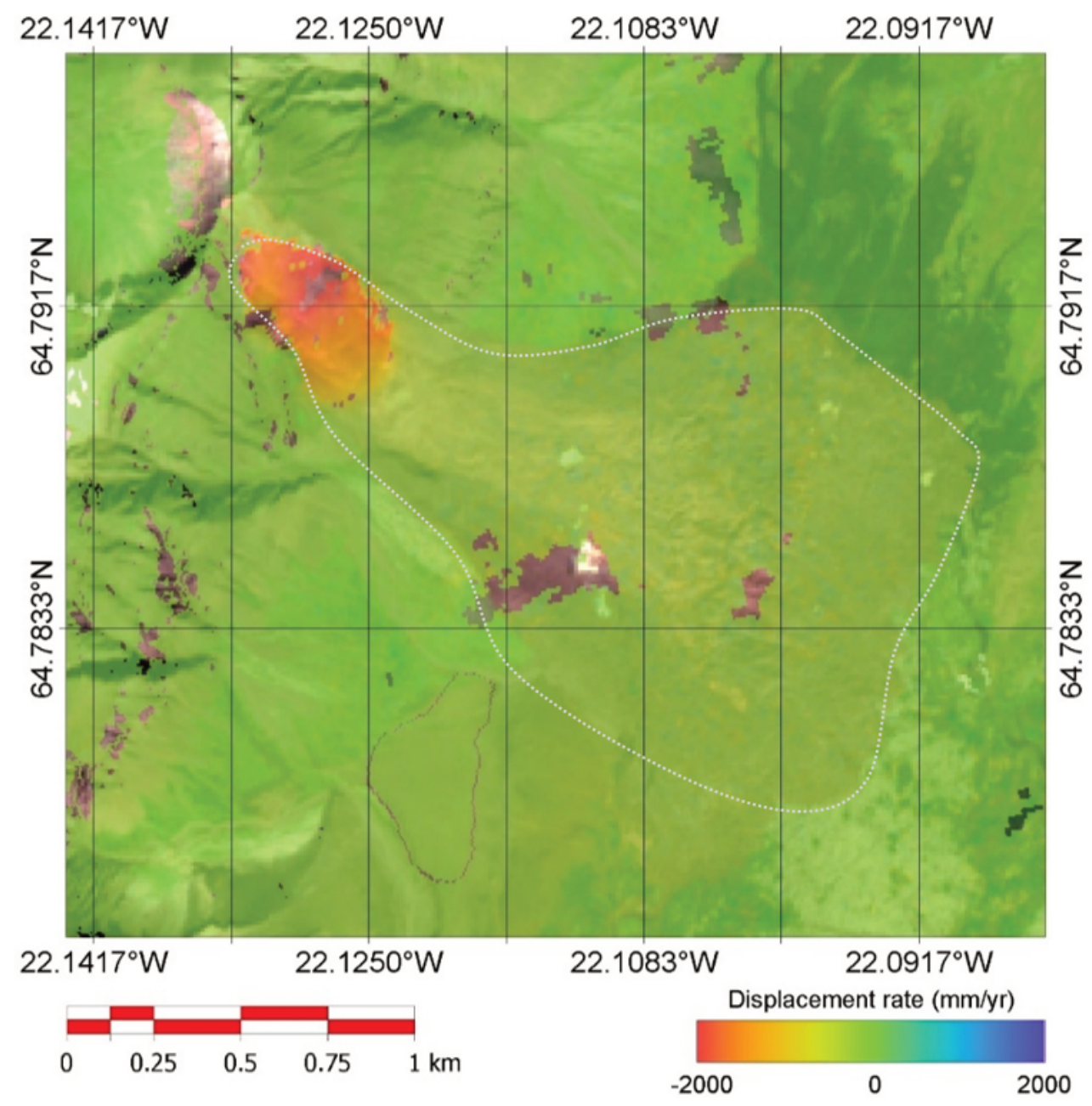

(a) 


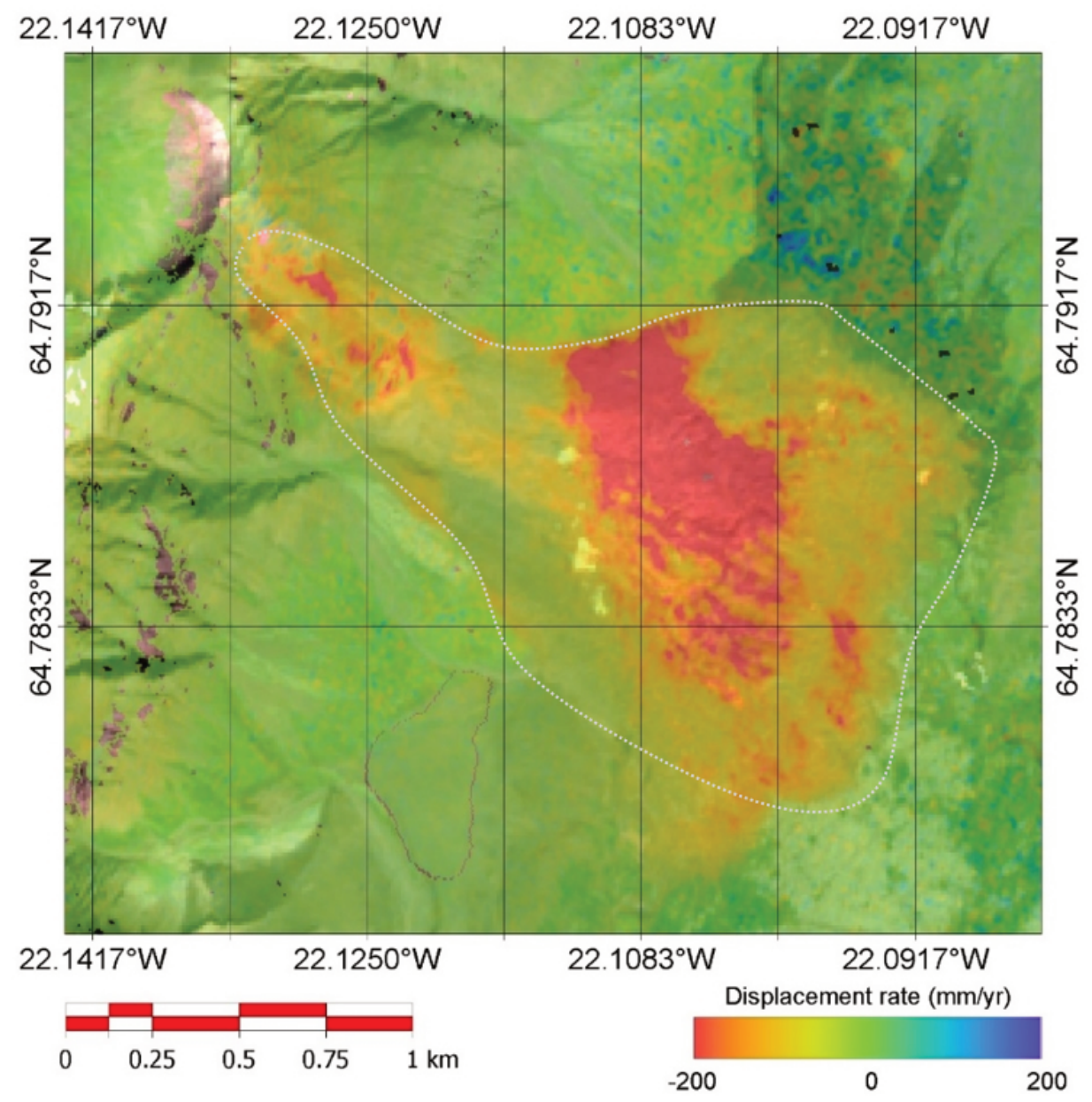

(b)

Figure 5 InSAR displacement rates for the Fagraskógarfjall landslide overlain on a post-failure Sentinel-2 optical image. Contains modified Copernicus Sentinel data, 2019. (a) Pre-failure displacement rate for the time period 10 July 2017 to 26 October 2017; (b) Post-failure displacement rate for the time period 11 July 2018 to 27 September 2018

In the summer of 2017, the slope had accelerated substantially compared to the previous two years (Figures 6c and 7). Between 10 July 2017 and 26 October 2017, the slope moved up to $450 \mathrm{~mm}$ towards the satellite LOS (Figure 6c). The area of fastest displacement on the landslide was in the centre of the landslide and it corresponds with a natural break where the slope angle increased. It was possible to determine the greater rate of displacement due to the greater frequency with which data was acquired (6-day as opposed to 12-day in previous years). Despite the higher frequency acquisitions, it was not possible to derive reliable measurements across the landslide on 2 October 2017. This is most likely due to a sudden acceleration of the landslide that exceeded the deformation gradient that InSAR can detect. This sudden acceleration most likely relates to higher rainfall in the region (Figure 7) in September 2017 (110 mm/month) compared to August ( $27 \mathrm{~mm} / \mathrm{month}$ ) and October ( $38 \mathrm{~mm} / \mathrm{month})$. Rainfall will have the combined effect of loading the landslide and increasing the porewater pressure within and at the base of the landslide. 


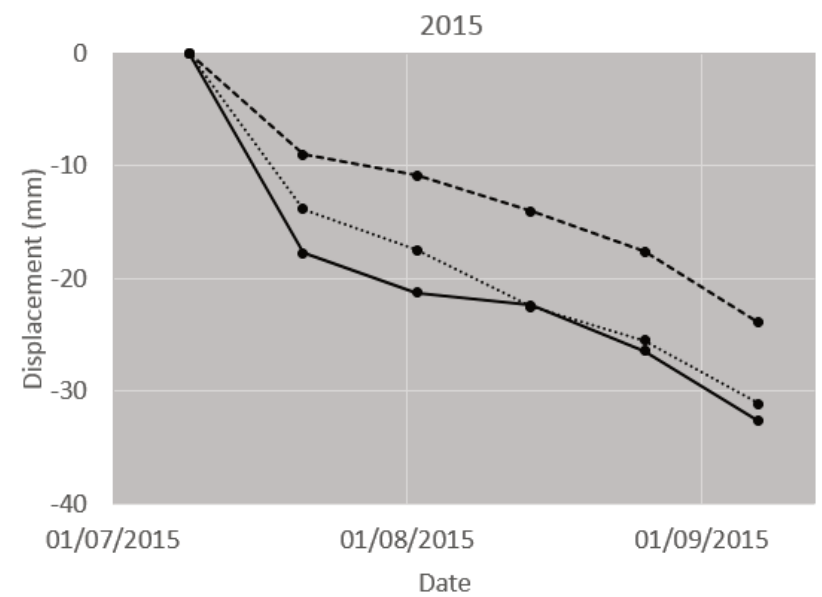

(a)

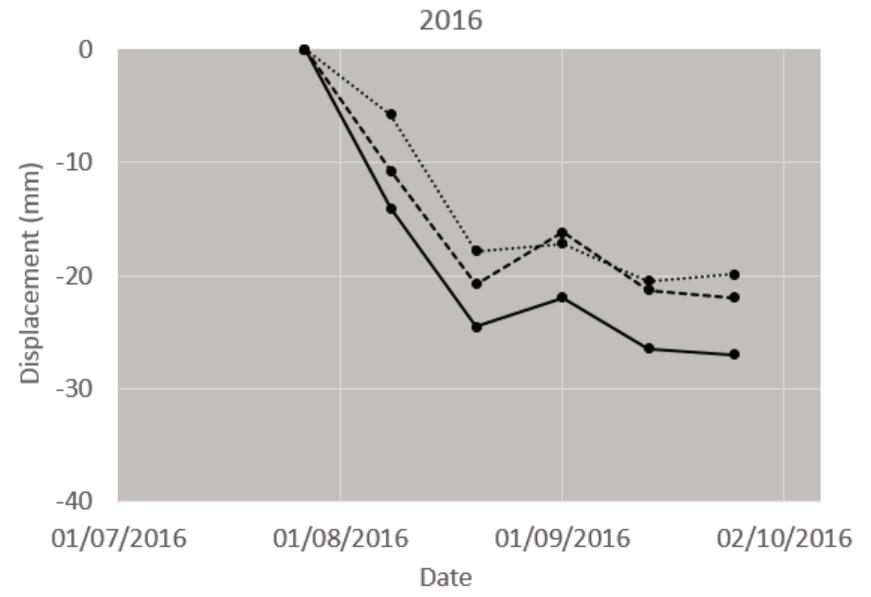

(b)

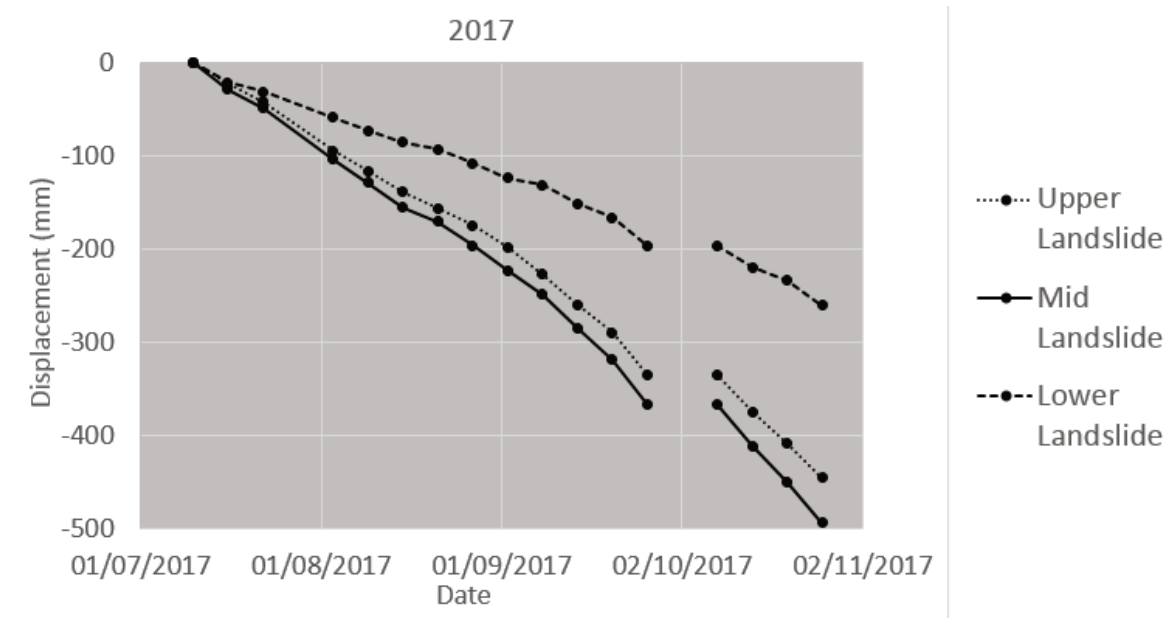

(c)

Figure 6 Displacement of the Fagraskógarfjall landslide for (a) 2015, (b) 2016, and (c) 2017. Measurements are taken at the upper, mid-point and lower landslide

It was not possible to generate reliable measurements of the landslide in 2018 prior to failure of the slope. The slope was clearly moving in 2018 but at such a rate that it was not possible to generate reliable measurements. However, it was possible to monitor the extent of the area that was moving up to failure on the 7 July 2018. It is noteworthy that 2018 had higher than usual rainfall and this may have ultimately contributed to the mass failure of the slope.

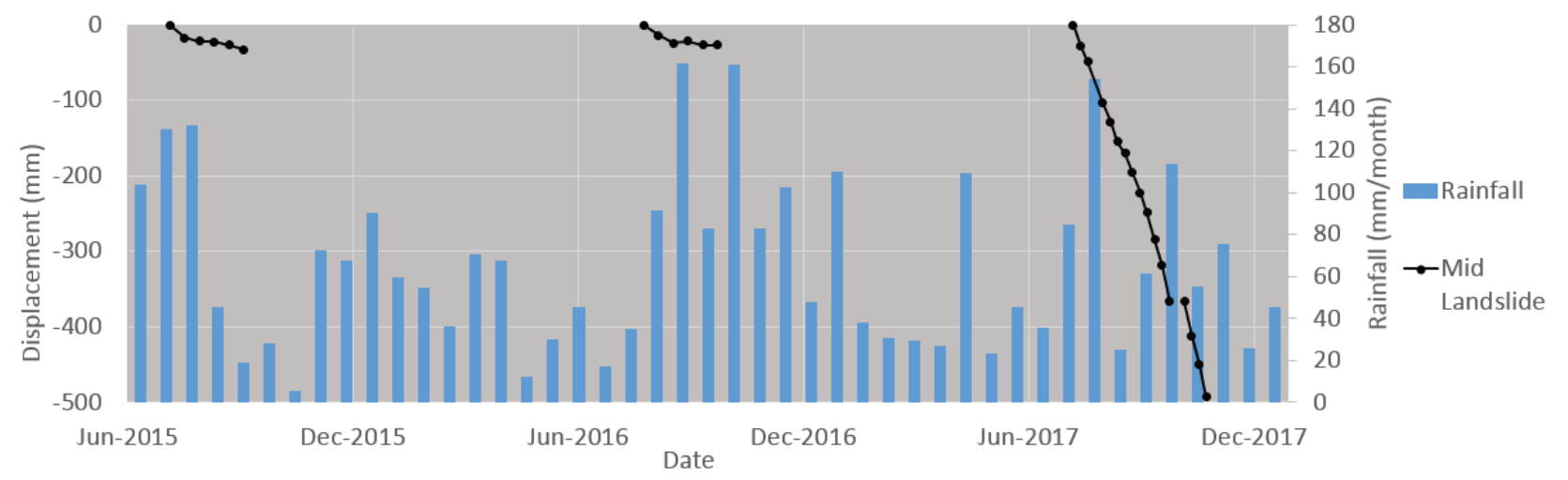

Figure 7 Displacement of the Fagraskógarfjall landslide between 2016 and 2017, and monthly rainfall for the region 
After the failure occurred, the headwall scarp was observed to still be moving. Up to $300 \mathrm{~mm} /$ year of displacement was detected on the headwall in the three months after the slope failure (Figure 5b). This further displacement demonstrates that there was a further hazard in this area, even after the failure occurred.

\section{Conclusion}

InSAR can be used effectively to determine the displacement history of a landslide, as well as provide ongoing monitoring of slope displacement. In the first case, we have been able to determine the three-year displacement history of the Limnes landslide. This landslide has a complex history with regular changes in the acceleration/deceleration of slope displacement. We also determined that the majority of the displacement is horizontal rather than vertical. In the second case, we have shown that despite difficult climatic conditions and a fast-moving landslide, InSAR can be an effective tool for monitoring remote landslides that may be difficult to monitor using ground-based monitoring. However, we have seen that for time periods when the deformation gradient is too steep, it is not possible to generate reliable InSAR measurements. In both cases, the landslides showed correlations between the volume of rainfall and the velocity of the slope displacement.

Both studies show that despite different landslide mechanisms and environmental settings, InSAR has been capable of mapping and monitoring displacements associated with two very different landslides, highlighting the value of this technique in combination with rainfall triggering mechanisms and, potentially, in combination with other monitoring data, which was not the focus of this study.

InSAR provides a useful tool and should be considered as complementary to existing ground-based monitoring systems, where they can be feasibly used. The expanding availability of open-access SAR data also means that InSAR monitoring is becoming increasingly feasible and cost-effective, whether applied to slope monitoring in mining, civil engineering or geological hazards.

\section{Acknowledgement}

The authors acknowledge the ESA Copernicus Sentinel mission, NASA and the Polar Geospatial Centre for the provision of data. We also thank Gareth Hearn for his knowledge of the Limnes landslide.

\section{References}

Bamler, R \& Hart, P 1998, 'Synthetic aperture radar interferometry', Inverse Problems, vol. 14, no. 4, pp. R1-R54.

Hanssen, RF 2001, Radar Interferometry: Data Interpretation and Error Analysis, Kluwer, Dordrecht.

Hearn, GJ, Larkin, H, Hadjicharalambous, K, Papageorgiou, A \& Zoi, GE 2018, 'Proving a landslide: ground behaviour problems at Pissouri, Cyprus', Quarterly Journal of Engineering Geology and Hydrology, vol. 51, pp. 461-482.

Icelandic Meteorological Office 2018, Displacements in Fagraskógarfjall for some time before the landslide fell, viewed 18 October 2019, https://en.vedur.is/about-imo/news/displacements-in-fagraskogarfjall-for-some-time-before-the-landslide-fell

Larkin, HE \& Hearn, GJ 2019, 'The use of remote sensing for strengthening geomorphological interpretation of ground behaviour problems at Limnes, Pissouri, SW Cyprus', in G Gazetas \& I Anastasopoulos (eds), Proceedings of the 2nd International Conference on Natural Hazards and Infrastructure, National Technical University of Athens, Athens.

Jarvis, A, Reuter, HI, Nelson, A \& Guevara, E 2008, 'Hole-filled SRTM for the globe Version 4', CGIAR Consortium for Spatial Information, http://srtm.csi.cgiar.org

Peridikou, S \& Kouhartsiouk, D 2019, 'Landslide risk evaluation in Cyprus using satellite radar interferometry: the "Rantkat" project', Proceedings of the XVII European Conference on Soil Mechanics and Geotechnical Engineering, Icelandic Geotechnical Society, Reykjavik.

Porter, C, Morin, P, Howat, I, Noh, M-J, Bates, B, Peterman, K, ... \& Bojesen, M 2018, ArcticDEM, Harvard Dataverse, https://doi.org/10.7910/DVN/OHHUKH,

Rosen, P, Hensley, S, Joughin, I, Li, F, Madsen, S, Rodriguez, E \& Goldstein, R 2000, 'Synthetic aperture radar interferometry', Proceedings of IEEE, vol. 88, no. 3, pp. 333-382. 
Utilising satellite-based techniques to identify and monitor slope

$\mathrm{H}$ Larkin et al. instabilities: the Fagraskógarfjall and Limnes landslides 